\title{
Reducing end-group of cellulose as a reactive site for thermal discoloration
}

AUTHOR(S):

Matsuoka, Seiji; Kawamoto, Haruo; Saka, Shiro

\section{CITATION:}

Matsuoka, Seiji ...[et al]. Reducing end-group of cellulose as a reactive site for thermal discoloration. Polymer Degradation and Stability 2011, 96(7): 1242-1247

\section{ISSUE DATE:}

2011-07

URL:

http://hdl.handle.net/2433/141991

\section{RIGHT:}

(c) 2011 Elsevier Ltd.; この論文は出版社版でありません。引用の際には 出版社版をご確認ご利用ください。; This is not the published version. Please cite only the published version. 
Reducing end-group of cellulose as a reactive site for thermal discoloration

Seiji Matsuoka, Haruo Kawamoto*, Shiro Saka

Graduate School of Energy Science, Kyoto University, Yoshida-honmachi, Sakyo-ku, Kyoto 606-8501, Japan

*Corresponding author.

Tel/Fax: +81-75-753-4737

E-mail: kawamoto@energy.kyoto-u.ac.jp 


\begin{abstract}
:
Thermal discoloration of cellulose (Avicel PH-101 and Whatman No. 42 filter paper) was studied in $\mathrm{N}_{2}$ at $160-280{ }^{\circ} \mathrm{C}$ with glycerol-treated and $\mathrm{NaBH}_{4}$-reduced samples, to understand the role of the reducing end. Thermal discoloration of glycerol-treated Avicel PH-101, in which some of the reducing ends were converted into glycosides (non-reducing ends), was suppressed compared with the original cellulose, and the level of suppression was directly related to the extent of glycosylation of the reducing ends. The stabilization efficiency of glycerol-treated Whatman No. 42 filter paper suggested that the reducing ends newly formed by reduction of the degree of polymerization (DP) (to about 200) during heat treatment contributed to the discoloration. The important role of the reducing ends in thermal discoloration was supported by the stabilization of Avicel PH-101 by reduction with $\mathrm{NaBH}_{4}$ (giving a reducing end content that was $2 \%$ of that of the original cellulose). Thermally induced discoloration was also inhibited by heating cellulose in suspension in the polyether tetraethyleneglycol dimethylether, which has been reported to inhibit the thermal degradation of reducing sugars.
\end{abstract}

\title{
Keywords:
}

Cellulose; Thermal discoloration; Reducing end; Stabilization; Thermal glycosylation 


\section{Introduction}

Cellulose is a major component of plant cell walls, and has been utilized in the paper, textile and plastics/chemicals (as derivatives) industries [1]. Due to its renewable character, cellulose utilization is expected to expand in broad areas of technology. For example, use of cellulose as a reinforcing material for plastics attracts a great deal of attention because of its favorable mechanical properties such as high tensile strength [2-4].

Discoloration of cellulose is sometimes problematic in preparation of cellulose-polymer composites [5-8]. Thermal degradation of cellulose is known to occur even at temperatures lower than $200{ }^{\circ} \mathrm{C}$. Evolution of water, $\mathrm{CO}$ and $\mathrm{CO}_{2}[9,10]$ and reduction of the degree of polymerization (DP) $[9,10]$ have been reported, together with discoloration (yellowing) $[11,12]$ in this temperature range. Consequently, the synthetic polymers that can be used for composite preparation with cellulose are limited to those with low melting points such as polyethylene and polypropylene [13]. The processing temperature is also limited to below $230{ }^{\circ} \mathrm{C}$ [5].

We reported previously that the reducing ends of Avicel PH-101 microcrystalline cellulose were converted into glycosides by heat treatment with alcohols at temperatures $>140{ }^{\circ} \mathrm{C}$ [14]. Interestingly, the resulting alcohol-treated cellulose samples resisted discoloration on reheating at 240 and $280{ }^{\circ} \mathrm{C}$. These results suggest that the cellulose reducing end is a reactive site in discoloration of cellulose at these temperatures.

We also found that reducing sugars were stabilized in polyether against thermal degradation including browning and polysaccharides and char formation [15]. This unexpected result was explained by the action of the ether oxygens as proton acceptors. This prevents proton donation to the oxygen atoms of the sugar through intra- and intermolecular hydrogen bonding, which may inhibit acid-catalyzed glycosylation and dehydration reactions. Such a stabilization effect is also expected at the cellulose reducing ends when heat treatment of cellulose is conducted in polyether.

In the present study, thermal discoloration of cellulose was investigated systematically with glycerol-treated and $\mathrm{NaBH}_{4}$-reduced cellulose samples, to understand the role of the reducing end in thermal discoloration. Thermal discoloration of cellulose in the polyether tetraethyleneglycol dimethylether (TEGDE) was also compared with that in neat conditions.

\section{Experimental}

\subsection{Materials}

Avicel PH-101 (Asahi Kasei Co., Ltd., Japan) and Whatman No.42 filter paper (Whatman PLC, UK) were used as cellulose samples. The filter paper was cut into small pieces $(3 \times 3 \mathrm{~mm})$, which were oven-dried at $105^{\circ} \mathrm{C}$ for $24 \mathrm{~h}$ before use. Glycerol was purchased from Nacalai Tesque Inc., Japan. TEGDE was purchased from Tokyo Chemical Industry Co., Ltd., Japan.

\subsubsection{Glycerol-treated cellulose}

Glycerol-treated cellulose was prepared according to the method reported in our previous paper [14]. Cellulose $(100 \mathrm{mg})$ and glycerol $(200 \mathrm{mg})$ were placed at the bottom of a Pyrex glass tube reactor (internal diameter $8.0 \mathrm{~mm}$, wall thickness $1.0 \mathrm{~mm}$, length $300 \mathrm{~mm}$ ). After the air inside the reactor was replaced with $\mathrm{N}_{2}$ using an aspirator 
connected through a three-way tap, the reactor was inserted into a muffle furnace preheated to various temperatures in the range $120-280{ }^{\circ} \mathrm{C}$, through a small hole at the top of the furnace. After heating for $30 \mathrm{~min}$ (for Avicel PH-101) or $60 \mathrm{~min}$ (Whatman No.42 filter paper), the reactor was removed from the furnace and immediately cooled with flowing air (30 s) and then in cold water (30 s). The treated cellulose samples were washed with water $(5 \times 2 \mathrm{~mL})$ then freeze-dried.

\subsection{2 $\mathrm{NaBH}_{4}$-reduced cellulose}

The reducing ends of Avicel $\mathrm{PH}-101$ were reduced with $\mathrm{NaBH}_{4}$ according to the reported method [14]. Sodium borohydride $(50 \mathrm{mg})$ was added to a suspension of Avicel $\mathrm{PH}-101(1 \mathrm{~g})$ in $0.1 \mathrm{~N}$ sodium carbonate buffer $(\mathrm{pH} 10,20 \mathrm{~mL})$ and stirred at $80{ }^{\circ} \mathrm{C}$ for $5 \mathrm{~h}$. The $\mathrm{pH}$ of the reaction mixture was adjusted to 4.0 by addition of aq. $1 \mathrm{~N} \mathrm{HCl}$ to terminate the reaction. After further stirring at $80{ }^{\circ} \mathrm{C}$ for $30 \mathrm{~min}$, the suspension was neutralized by adding one drop of saturated aq. $\mathrm{NaHCO}_{3}$ solution. These procedures were performed twice to complete the reduction. The $\mathrm{NaBH}_{4}$-reduced cellulose sample was washed with $20 \mathrm{~mL}$ of aq. $0.001 \mathrm{~N} \mathrm{HCl}$, then with water $(5 \times 20 \mathrm{~mL})$. After repeating the washing procedure one to five times, the sample was freeze-dried. Based on data from reducing group analysis by the 2,2'-bicinchoninic acid (BCA) method [14], the reducing end content of the reduced cellulose was only $2 \%$ of that of the unmodified cellulose.

The $\mathrm{Na}$ and $\mathrm{B}$ content of reduced samples with different washing times was quantified as follows. The reduced sample $(100 \mathrm{mg})$ was incinerated in air in a muffle furnace at $600{ }^{\circ} \mathrm{C}$ for $2 \mathrm{~h}$. The resulting ash was solubilized in distilled water $(10 \mathrm{~mL})$ and analyzed by ICP-MS with an Agilent 7500cs ICP-MS instrument.

\subsection{Heat treatment}

Heat treatment of various glycerol-treated and $\mathrm{NaBH}_{4}$-reduced cellulose samples (20 mg) was conducted with a similar procedure to that described in section 2.1.1 (except for use of glycerol) for preparation of glycerol-treated cellulose samples. After heat treatment $\left(\mathrm{N}_{2} / 120-280^{\circ} \mathrm{C} / 30\right.$ min for Avicel PH-101 or 60 min for Whatman filter paper), the reactor was cooled with flowing air $(30 \mathrm{~s})$ and then in cold water. The cellulose samples were then analyzed without purification. Avicel PH-101 (100 mg) suspended in TEGDE (200 mg) was also heated in $\mathrm{N}_{2}$ at $160-280{ }^{\circ} \mathrm{C}$. These cellulose samples were filtered and washed with water $(1.0 \mathrm{~mL})$ to remove TEGDE, then freeze-dried.

\subsection{Colorimetric analysis}

Color was measured with a ZE6000 color meter (Nippon Denshoku Industries Co., Ltd.). CIELAB parameters ( $\mathrm{L}^{*}, \mathrm{a}^{*}$, and $\mathrm{b}^{*}$ ) were determined in reflectance mode (JIS $\mathrm{Z}-8722)$ using illuminant $\mathrm{C}$ and $2^{\circ}$ observer angle. Total color difference $\left(\Delta \mathrm{E}^{*}\right)$ was calculated from the equation:

$$
\Delta \mathrm{E}^{*}=\left[\left(\Delta \mathrm{L}^{*}\right)^{2}+\left(\Delta \mathrm{a}^{*}\right)^{2}+\left(\Delta \mathrm{b}^{*}\right)^{2}\right]^{1 / 2}
$$

\subsection{Gel permeation chromatography (GPC)}

Molecular weight (MW) distribution was evaluated by GPC for phenyl carbamate derivatives of the celluloses. Sample $(5 \mathrm{mg})$ and phenyl isocyanate $(0.2 \mathrm{~mL})$ were added to pyridine $(2 \mathrm{~mL})$, and the mixture stirred at $80{ }^{\circ} \mathrm{C}$. After $24 \mathrm{~h}$, the reaction mixture 
became a yellow transparent solution. Methanol $(0.5 \mathrm{~mL})$ was then added to terminate the reaction, and the solvent was removed by evaporation in vacuo to give a dark yellow syrup. The phenyl carbamate derivatives were dissolved in tetrahydrofuran (THF), and analyzed by GPC with a Shimadzu LC-10A instrument under the following chromatographic conditions: column, Shodex LF-804; column temperature, $40{ }^{\circ} \mathrm{C}$; eluent, THF; flow rate, $1.0 \mathrm{~mL} / \mathrm{min}$; detector, $\mathrm{UV}_{254 \mathrm{~nm}}$.

\section{Results and discussion}

\subsection{Glycerol-treated cellulose}

Figure 1 shows photographs of various glycerol-treated cellulose samples (Avicel and Whatman filter paper) that were prepared under $\mathrm{N}_{2}$ at $120-280{ }^{\circ} \mathrm{C}$. The photographs in the (b) lines are the glycerol-treated samples after heat treatment in $\mathrm{N}_{2}$ at $240{ }^{\circ} \mathrm{C}$ for $30 \mathrm{~min}$ (Avicel) or $60 \mathrm{~min}$ (Whatman filter paper). The longer heating time for Whatman filter paper was used due to the higher stability of the filter paper to thermal discoloration. Figure 2 summarizes the changes in the CIE color parameters $\left(\mathrm{L}^{*}, \mathrm{a}^{*}\right.$ and $\left.b^{*}\right)$ of these samples after heat treatment. Decrease of $\mathrm{L}^{*}$ indicates brightness reduction; increase of $\mathrm{a}^{*}$ and $\mathrm{b}^{*}$ arises from color changes to red and yellow, respectively.

Untreated Avicel PH-101 was severely discolored after heat treatment at $240{ }^{\circ} \mathrm{C}$ for $30 \mathrm{~min}$ : $\mathrm{L}^{*}$ decreased from 96.3 to 64.4 , and $\mathrm{a}^{*}$ and $\mathrm{b}^{*}$ increased to 10.0 (from -0.6) and 30.7 (from 2.3), respectively. These parameter changes are consistent with the change of appearance in the control experiment. The glycerol-treated samples were stabilized toward this thermal discoloration, and the stabilization efficiency increased along with the increase in the glycerol treatment temperature. Changes in the CIE parameters also decreased for the glycerol-treated samples (Fig. 2).

In our previous paper [14], glycerol treatment at high temperature was reported to convert the cellulose reducing ends into glycosides via thermal glycosylation reaction. The reactivity of Avicel PH-101 to thermal glycosylation was not homogeneous. About $20 \%$ of the reducing ends reacted with glycerol at $140{ }^{\circ} \mathrm{C}$, while the remainder became reactive at higher temperatures $\left(>200^{\circ} \mathrm{C}\right)$. This may arise from the crystalline nature of cellulose. The change in the reducing end content of Avicel PH-101 shown in Fig. 3 is consistent with the tendency of this thermal glycosylation. Interestingly, the color difference $\left(\Delta \mathrm{E}^{*}\right)$ plotted against the glycerol treatment temperature exhibited the same trend as that of the reducing end content. These results strongly suggest that the cellulose reducing end is an important reaction site for thermal discoloration.

Inhibition of thermal discoloration was observed for the glycerol-treated Whatman filter paper samples (Figs. 1 and 2). However, the relationship between the stabilization efficiency and the glycerol treatment temperature was different from that for Avicel PH-101. Although the CIE parameter changes after heat treatment were reduced with increase in the glycerol treatment temperature in the case of Avicel PH-101 (Fig. 2), the CIE parameter changes for Whatman filter paper were not simply related to temperature. The stabilization efficiency of Whatman filter paper became greater at temperatures $>200{ }^{\circ} \mathrm{C}$.

These differing results can be explained by considering the change in DP of Whatman filter paper during glycerol treatment and heat treatment. Figure 4 shows the results of GPC analysis of the glycerol-treated Whatman filter paper samples. The chromatogram obtained from heat treatment of untreated cellulose (control sample) at 
$240{ }^{\circ} \mathrm{C}$ for $60 \mathrm{~min}$ is also included. The degree of polymerization (DP) of cellulose is known to be reduced during heat treatment to about the leveling-off DP ( 200) [16]. The DP of Avicel PH-101 had already attained the leveling-off DP, since the preparation process included a mild acid hydrolysis step. By contrast, DP reduction was observed for Whatman filter paper (control) during heat treatment. The resulting newly formed reducing ends may contribute to thermal discoloration.

Similar DP reduction was also observed in preparation of the glycerol-treated Whatman filter paper samples, and the reduction became significant with increase in the treatment temperature. It was found previously [14] that the newly formed ends in glycerol are not reducing ends but glycosides with glycerol, since solvolysis takes place in glycerol. Thus the higher stabilization efficiency of the glycerol-treated Whatman filter paper samples obtained at 200,240 and $280{ }^{\circ} \mathrm{C}$ is explainable as follows. Reducing end formation resulting from the DP-reduction was not important in heat treatment of these cellulose samples, because their DPs were already reduced to around the leveling-off DP and their reducing ends were blocked as glycosides.

\subsection{Influence of $\mathrm{NaBH}_{4}$ reduction}

Cellulose reducing ends can be converted into glucitol moieties by reduction with $\mathrm{NaBH}_{4}$ [14]. To confirm the important role of the reducing ends, the thermal discoloration behavior of $\mathrm{NaBH}_{4}$-reduced Avicel $\mathrm{PH}-101$ was compared with that of the original cellulose. Treatment of Avicel $\mathrm{PH}-101$ with $\mathrm{NaBH}_{4}$ in aqueous $0.1 \mathrm{~N}$ sodium carbonate buffer ( $\mathrm{pH} 10$ ) decreased the reducing end content to about $2 \%$ of that of the original cellulose. Figure 5 shows the boron (B) and sodium (Na) contents in $\mathrm{NaBH}_{4}$-reduced Avicel PH-101 samples prepared with different washing times with aqueous $0.001 \mathrm{~N} \mathrm{HCl}$ solution. The $\mathrm{B}$ and $\mathrm{Na}$ contents were reduced from 650 and 280 ppm (no acid washing) to around 20 and 5 ppm, respectively, after repeating the acid washing procedure more than twice. Since the B and $\mathrm{Na}$ contents in the original Avicel PH-101 were $2.7 \mathrm{ppm}(\mathrm{B})$ and $0.7 \mathrm{ppm}(\mathrm{Na})$, these elements are contaminants from $\mathrm{NaBH}_{4}$. Boronate and its $\mathrm{Na}$ salt remaining in the reduced cellulose samples could not be removed completely by washing with water, but acid washing can decompose the boronates that are formed with cellulose hydroxyl groups.

Figure 6 shows photographs of the $\mathrm{NaBH}_{4}$-reduced samples after heat treatment in $\mathrm{N}_{2}$ at $240{ }^{\circ} \mathrm{C}$ for $30 \mathrm{~min}$, together with their color difference $\left(\Delta \mathrm{E}^{*}\right)$ parameters. Thermal discoloration was clearly inhibited for the $\mathrm{NaBH}_{4}$-reduced Avicel PH-101 samples, and the extent of inhibition was dependent on the acid washing time, hence on the $\mathrm{B}$ and $\mathrm{Na}$ contents. Generally, inorganic substances enhance char formation [17-21]. Thus without acid washing, the residual inorganic substances arising from $\mathrm{NaBH}_{4}$ treatment would enhance discoloration. The lower stabilization efficiency of this sample may arise from such an influence of the inorganic substances. Stabilization against thermal discoloration observed for the $\mathrm{NaBH}_{4}$-reduced Avicel $\mathrm{PH}-101$ supports the hypothesis that the reducing end is a reactive site for thermal discoloration.

\subsection{Heat treatment in polyether}

Matsuoka et al. [15] found that thermal degradation of reducing sugars is inhibited in polyether, and proposed an inhibition mechanism in which an aprotic polyether acts as a base through hydrogen bonding to the hydroxyl groups of a sugar. This prevents proton donation to the oxygen atoms of sugar, which results in inhibition of 
acid-catalyzed reactions such as glycosylation and dehydration. These findings suggest that the reducing ends of cellulose can be stabilized in polyether.

Figure 7 shows the discoloration behavior of Avicel PH-101 in TEGDE; the corresponding changes in the CIE parameters are summarized in Fig. 8. Discoloration of Avicel PH-101 tended to be enhanced by heat treatment for $30 \mathrm{~min}$ at the higher temperatures $\left(>200-240{ }^{\circ} \mathrm{C}\right.$ ), and at $280{ }^{\circ} \mathrm{C}$ the color became almost black. The temperature effect on this thermal discoloration was similar to that for thermal glycosylation in glycerol (Fig. 3). In accordance with the change in the appearance, L* decreased, and $\mathrm{a}^{*}$ and $\mathrm{b}^{*}$ increased except for $\mathrm{b}^{*}$ at $280{ }^{\circ} \mathrm{C}$. Thermal discoloration was effectively inhibited in TEGDE. The water-soluble portions including TEGDE obtained at 240 and $280{ }^{\circ} \mathrm{C}$ had a slightly yellow color, but the color intensity was not sufficient to explain the inhibition of discoloration by solubilization of the colored substances. Thus, polyether is effective for inhibition of the thermal discoloration of cellulose. These results also support the proposal that the reducing end plays an important role in thermal discoloration.

3.4 Role of reducing end in thermal discoloration of Avicel PH-101 and Whatman filter paper

As noted above, thermal discoloration was different for Avicel PH-101 and Whatman filter paper. The lower stability of Avicel PH-101 to thermal discoloration arose from the larger number of reducing ends in the cellulose molecules, many of which are formed during acid hydrolysis in the preparation process. Whatman filter paper with higher DP has fewer reducing ends, which may enhance stability to thermal discoloration to a greater extent than for Avicel PH-101. Thermal discoloration of Whatman filter paper became significant when DP-reduction to form additional reducing ends occurred during heat treatment.

Thermal glycosylation reactivity [14] indicated that most of the reducing ends in Avicel PH-101 become reactive at temperatures $>200-240{ }^{\circ} \mathrm{C}$, although about $20 \%$ of the reducing ends, probably in the non-crystalline region, are reactive even at $140{ }^{\circ} \mathrm{C}$. The former temperature range is that in which thermal expansion of cellulose crystallites becomes significant; thermal discoloration of Avicel PH-101 also became significant in that temperature range. These results suggest the interesting possibility that the reducing ends formed in the crystalline regions of cellulose contribute more to thermal discoloration than those in the non-crystalline regions.

\section{Conclusions}

The glycerol-treated cellulose samples (Avicel PH-101 and Whatman No.42 filter paper) whose reducing ends were converted into glycosides were stabilized against thermal discoloration. These results suggest that the reducing end is an important reactive site for thermal discoloration. This hypothesis is supported by the stabilization of Avicel PH-101 by $\mathrm{NaBH}_{4}$-reduction, and the inhibition of thermal discoloration of Avicel PH-101 in TEGDE, which is reported to inhibit the thermal degradation of reducing sugars.

\section{Acknowledgments}


This work was supported by the Kyoto University Global COE program of "Energy Science in the Age of Global Warming", and a Grant-in-Aid for Scientific Research (B) (2) (No. 20380103 2008.4-2011.3). 


\section{References}

[1] Zugenmaier P. Crystalline cellulose and derivatives. Berlin: Springer-Verlag, 2007.

[2] Joshi S, Drzal L, Mohanty A, Arora S. Are natural fiber composites environmentally superior to glass fiber reinforced composites? Composites: Part A 2004;35(3):371-376.

[3] Siró I, Plackett D. Microfibrillated cellulose and new nanocomposite materials: a review. Cellulose 2010;17(3):459-494.

[4] Azizi Samir MAS, Alloin F, Dufresne A. Review of recent research into cellulosic whiskers, their properties and their application in nanocomposite field. Biomacromolecules 2005;6(2):612-626.

[5] Sapieha S, Pupo JF, Schreiber HP. Thermal degradation of cellulose-containing composites during processing. J Appl Polym Sci 1989;37(1):233-240.

[6] Urreaga JM, Matías MC, De La Orden MU, Munguía MAL, Sánchez CG. Effects of coupling agents on the oxidation and darkening of cellulosic materials used as reinforcements for thermoplastic matrices in composites. Polym Eng Sci 2000;40(2):407-417.

[7] Coutinho FM, Costa TH, Carvalho DL. Polypropylene-wood fiber composites: Effect of treatment and mixing conditions on mechanical properties. J Appl Polym Sci 1997;65(6):1227-1235.

[8] Quiévy N, Jacquet N, Sclavons M, Deroanne C, Paquot M, Devaux J. Influence of homogenization and drying on the thermal stability of microfibrillated cellulose. Polym Degrad Stab 2010;95(3):306-314.

[9] Major WD. The degradation of cellulose in oxygen and nitrogen at high temperatures. TAPPI 1958;41(9):530-537.

[10] Shafizadeh F, Bradbury AGW. Thermal degradation of cellulose in air and nitrogen at low temperatures. J Appl Polym Sci 1979;23(5):1431-1442.

[11] Shimazu F, Sterling C. Effect of wet and dry heat on structure of cellulose. J Food Sci 1966;31(4):548-551.

[12] Yatagai M, Zeronian SH. Effect of ultraviolet light and heat on the properties of cotton cellulose. Cellulose 1994;1(3):205-214.

[13] Bledzki AK, Gassan J. Composites reinforced with cellulose based fibres. Prog Polym Sci 1999;24(2):221-274.

[14] Matsuoka S, Kawamoto H, Saka S. Thermal glycosylation and degradation reactions occurring at the reducing ends of cellulose during low-temperature pyrolysis. Carbohydr Res 2011;346(2):272-279.

[15] Matsuoka S, Kawamoto H, Saka S. Retro-aldol-type fragmentation of reducing sugars preferentially occurring in polyether at high temperature: role of the ether oxygen as a base catalyst. Submitted.

[16] Antal MJ. Biomass pyrolysis: A review of the literature Part 1-Carbohydrate pyrolysis. Adv Solar Energy 1983;1:61-111.

[17] Tsuchiya Y, Sumi K. Thermal decomposition products of cellulose. J Appl Polym Sci 1970;14(8):2003-2013.

[18] Shafizadeh F, Furneaux RH, Cocharn TG, Scholl JP, Sakai Y. Production of levoglucosan and glucose from pyrolysis of cellulose materials. J Appl Polym Sci 1979;23(12):3525-3539.

[19] Varhegyi G, Antal MJ, Szekely T, Till F, Jakab E. Simultaneous thermogravimetric-mass spectrometric studies of the thermal decomposition of biopolymers. 1. Avicel cellulose in the presence and absence of catalysts. Energy Fuels 
1988;2(3):267-272.

[20] Shimada N, Kawamoto H, Saka S. Different action of alkali/alkaline earth metal chlorides on cellulose pyrolysis. J Anal Appl Pyrol 2008;81(1):80-87.

[21] Kawamoto H, Yamamoto D, Saka S. Influence of neutral inorganic chlorides on primary and secondary char formation from cellulose. J Wood Sci 2008;54(3):242-246. 
Figure Legends

Figure 1. Influence of the glycerol treatment temperature on thermal discoloration of glycerol-treated Avicel PH-101 and Whatman No.42 filter paper heat-treated at $240{ }^{\circ} \mathrm{C}$ in $\mathrm{N}_{2}$; (a) before, and (b) after heat treatment. Glycerol treatment conditions: cellulose (100 mg)/glycerol $(200 \mathrm{mg}) / \mathrm{N}_{2} / 10 \mathrm{~min}$ (Avicel PH-101) or 30 min (Whatman No.42 filter paper). Heat treatment time: 30 min (glycerol-treated Avicel PH-101) or 60 min (glycerol-treated Whatman No.42 filter paper.

Figure 2. Influence of the glycerol treatment temperature on CIE color parameters ( $\mathrm{L}^{*}, \mathrm{a}^{*}$, and $\left.\mathrm{b}^{*}\right)$ of glycerol-treated Avicel PH-101 and Whatman No.42 filter paper before (solid circles) and after (open circles) heat treatment at $240{ }^{\circ} \mathrm{C}$ in $\mathrm{N}_{2}$. Glycerol treatment conditions: cellulose $(100 \mathrm{mg}) /$ glycerol $(200 \mathrm{mg}) / \mathrm{N}_{2} / 10$ min (Avicel PH-101) or $30 \mathrm{~min}$ (Whatman No.42 filter paper). Heat treatment time: 30 min (Avicel PH-101) or 60 min (Whatman No.42 filter paper).

Figure 3. Influence of the glycerol treatment temperature on reducing group content (open circles) and $\Delta \mathrm{E}^{*}$ (solid circles) of glycerol-treated Avicel PH-101 [14] after heat treatment $\left(\mathrm{N}_{2} / 240{ }^{\circ} \mathrm{C} / 30 \mathrm{~min}\right)$. Glycerol treatment conditions: $\mathrm{N}_{2} / 10$ min.

$\dagger$ Measured by the 2,2'-bicinchoninic acid method and normalized to untreated cellulose (100\%).

Figure 4. Change in the GPC pattern (for phenyl carbamate derivatives) after glycerol treatment of Whatman No.42 filter paper in $\mathrm{N}_{2}$ at various temperatures for $30 \mathrm{~min}$.

* Heat treatment condition: $\mathrm{N}_{2} / 240{ }^{\circ} \mathrm{C} / 60$ min.

Figure 5. Influence of the number of washings of $\mathrm{NaBH}_{4}$-reduced Avicel PH-101 on the $\mathrm{Na}$ (solid circles) and $\mathrm{B}$ (open circles) contents after heat treatment $\left(\mathrm{N}_{2} / 240{ }^{\circ} \mathrm{C} / 30 \mathrm{~min}\right)$. Washing condition: $0.001 \mathrm{~N} \mathrm{HCl}(2 \mathrm{~mL})$, then water $(5 \times 2$ $\mathrm{mL})$.

Figure 6. Influence of the number of washings of $\mathrm{NaBH}_{4}$-reduced Avicel $\mathrm{PH}-101$ on discoloration and total color difference $\left(\Delta \mathrm{E}^{*}\right)$ after heat treatment $\left(\mathrm{N}_{2} / 240{ }^{\circ} \mathrm{C} / 30 \mathrm{~min}\right)$. Washing condition: $0.001 \mathrm{~N} \mathrm{HCl}(2 \mathrm{~mL})$, then water $(5 \times 2$ $\mathrm{mL})$.

Figure 7. Discoloration of Avicel PH-101 heated in tetraethyleneglycol dimethylether (TEGDE) under $\mathrm{N}_{2}$ at various temperatures for $30 \mathrm{~min}$.

* Avicel PH-101 (100 mg)/TEGDE (200 mg). After heat treatment, the cellulose sample was filtered, washed with 1 $\mathrm{mL}$ water, then freeze-dried; (a) residual cellulose; (b) filtrate+washings.

Figure 8. Changes of the CIE color parameters $\left(\mathrm{L}^{*}, \mathrm{a}^{*}\right.$, and $\left.\mathrm{b}^{*}\right)$ after heat-treatment of Avicel PH-101 in the presence 
(open circles) or absence (closed circles) of tetraethyleneglycol dimethylether (TEGDE) under $\mathrm{N}_{2}$ at various temperatures for $30 \mathrm{~min}$. The sample preparation conditions are given in the footnote to Figure 7. 
Glycerol-treated Avicel PH-101

(b)

Glycerol-treatment temperature $\left({ }^{\circ} \mathrm{C}\right)$

(a)

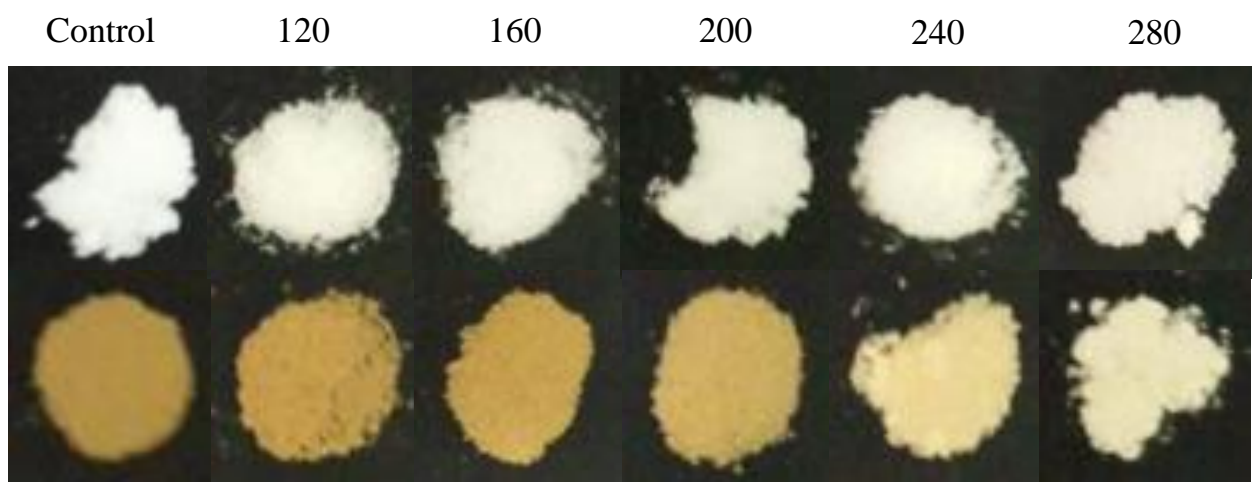

Glycerol-treated

(a)

Whatman No.42

filter paper

(b)

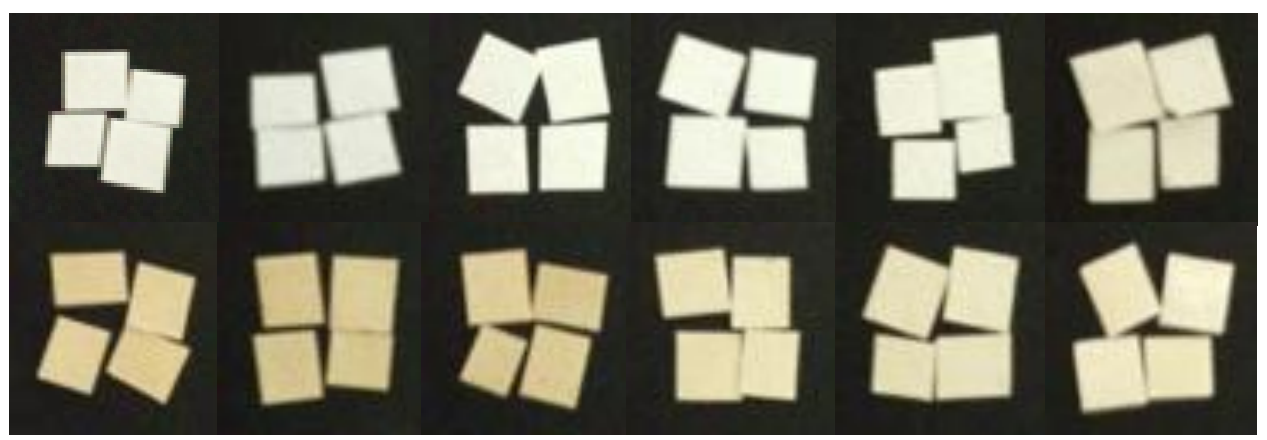

Figure 1. Influence of the glycerol treatment temperature on thermal discoloration of glycerol-treated Avicel PH-101 and Whatman No.42 filter paper heat-treated at $240{ }^{\circ} \mathrm{C}$ in $\mathrm{N}_{2}$; (a) before, and (b) after heat treatment. Glycerol treatment conditions: cellulose $(100 \mathrm{mg}) / \mathrm{glycerol}(200 \mathrm{mg}) / \mathrm{N}_{2} / 10 \mathrm{~min}$ (Avicel PH-101) or 30 min (Whatman No.42 filter paper). Heat treatment time: 30 min (glycerol-treated Avicel PH-101) or 60 min (glycerol-treated Whatman No.42 filter paper). 

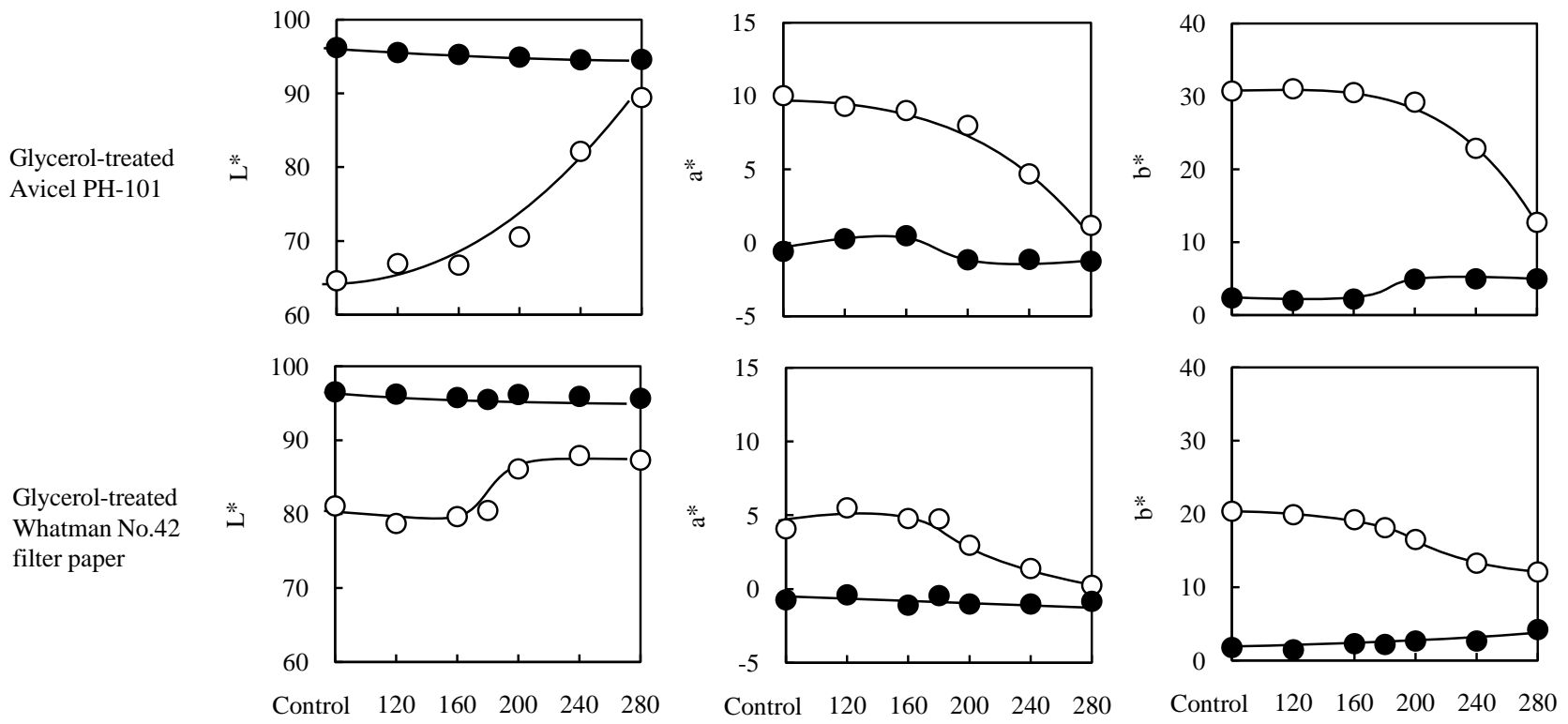

Glycerol-treatment temperature $\left({ }^{\circ} \mathrm{C}\right)$

Figure 2. Influence of the glycerol treatment temperature on CIE color parameters ( $\mathrm{L}^{*}, \mathrm{a}^{*}$, and $\left.\mathrm{b}^{*}\right)$ of glycerol-treated Avicel PH-101 and Whatman No.42 filter paper before (solid circles) and after (open circles) heat treatment at $240{ }^{\circ} \mathrm{C}$ in $\mathrm{N}_{2}$. Glycerol treatment conditions: cellulose $(100 \mathrm{mg}) / \mathrm{glycerol}(200 \mathrm{mg}) / \mathrm{N}_{2} / 10 \mathrm{~min}$ (Avicel PH-101) or $30 \mathrm{~min}$ (Whatman No.42 filter paper). Heat treatment time: 30 min (Avicel PH-101) or 60 min (Whatman No.42 filter paper). 


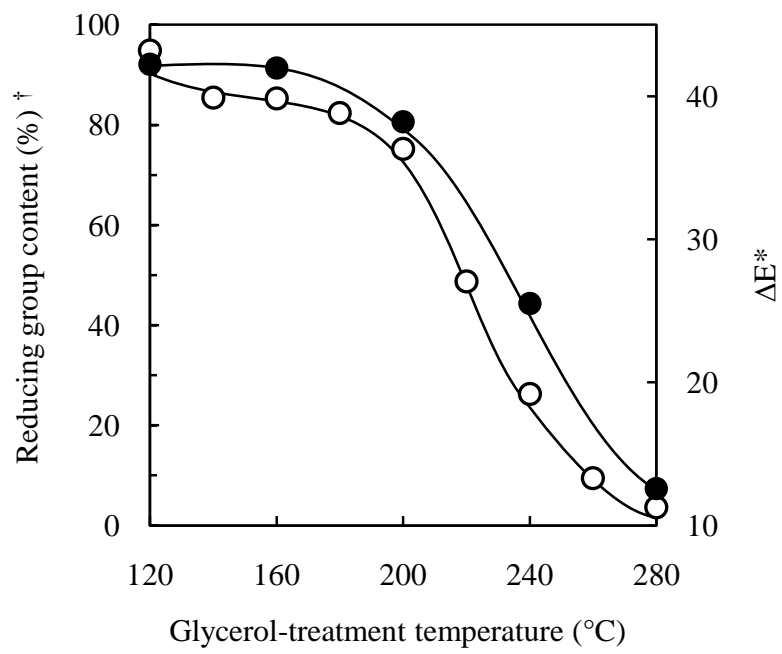

Figure 3. Influence of the glycerol treatment temperature on reducing group content (open circles) and $\Delta \mathrm{E}^{*}$ (solid circles) of glycerol-treated Avicel PH-101 [14] after heat treatment $\left(\mathrm{N}_{2} / 240{ }^{\circ} \mathrm{C} / 30 \mathrm{~min}\right)$. Glycerol treatment conditions: $\mathrm{N}_{2} / 10$ min.

$\dagger$ Measured by the 2,2'-bicinchoninic acid method and normalized to untreated cellulose (100\%). 


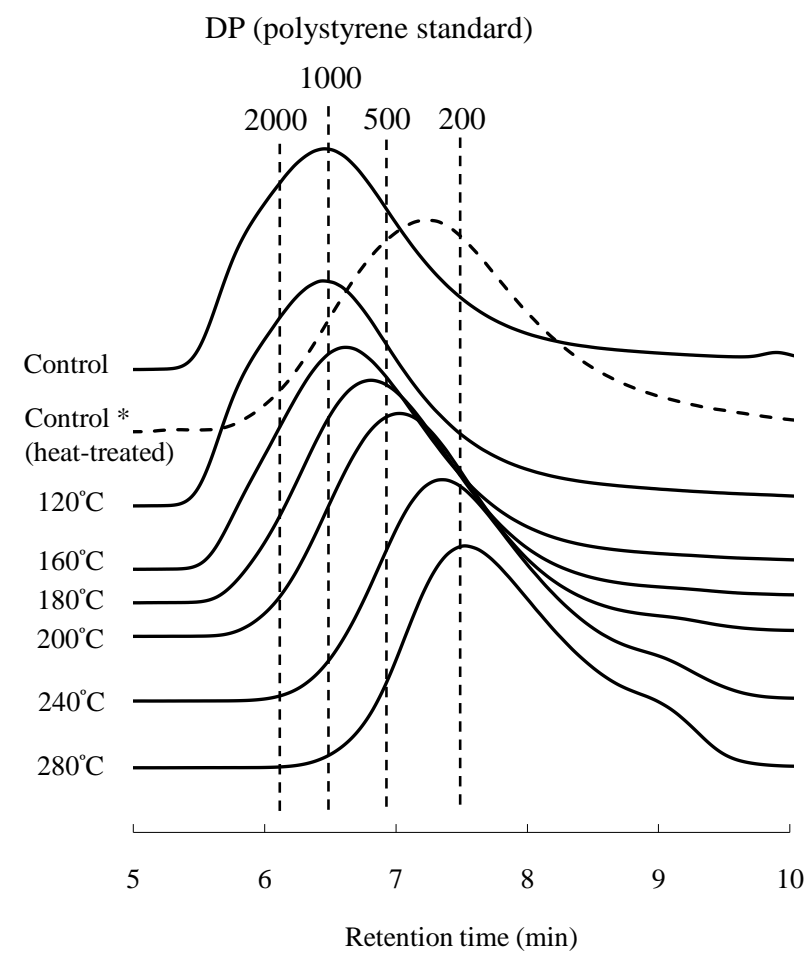

Figure 4. Change in the GPC pattern (for phenyl carbamate derivatives) after glycerol treatment of Whatman No.42 filter paper in $\mathrm{N}_{2}$ at various temperatures for $30 \mathrm{~min}$.

* Heat treatment condition: $\mathrm{N}_{2} / 240{ }^{\circ} \mathrm{C} / 60$ min. 


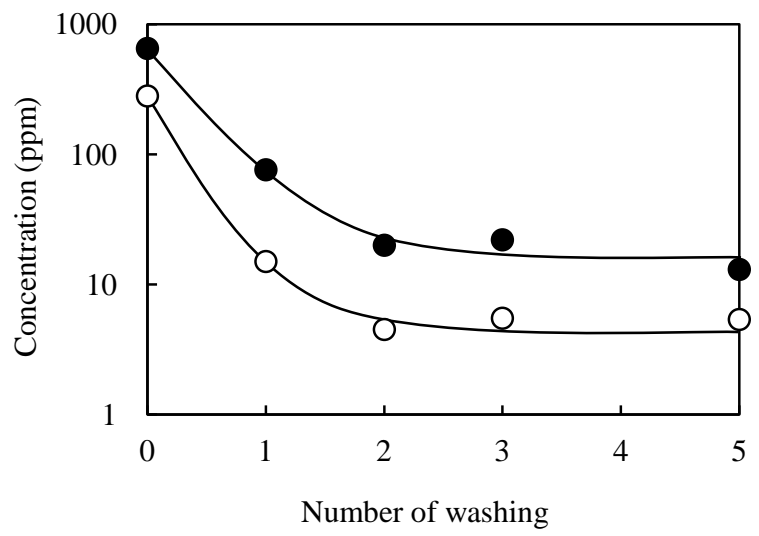

Figure 5. Influence of the number of washings of $\mathrm{NaBH}_{4}$-reduced Avicel PH-101 on the $\mathrm{Na}$ (solid circles) and $\mathrm{B}$ (open circles) contents after heat treatment $\left(\mathrm{N}_{2} / 240{ }^{\circ} \mathrm{C} / 30 \mathrm{~min}\right)$. Washing condition: $0.001 \mathrm{~N} \mathrm{HCl}(2 \mathrm{~mL})$, then water $(5 \times 2$ $\mathrm{mL})$. 


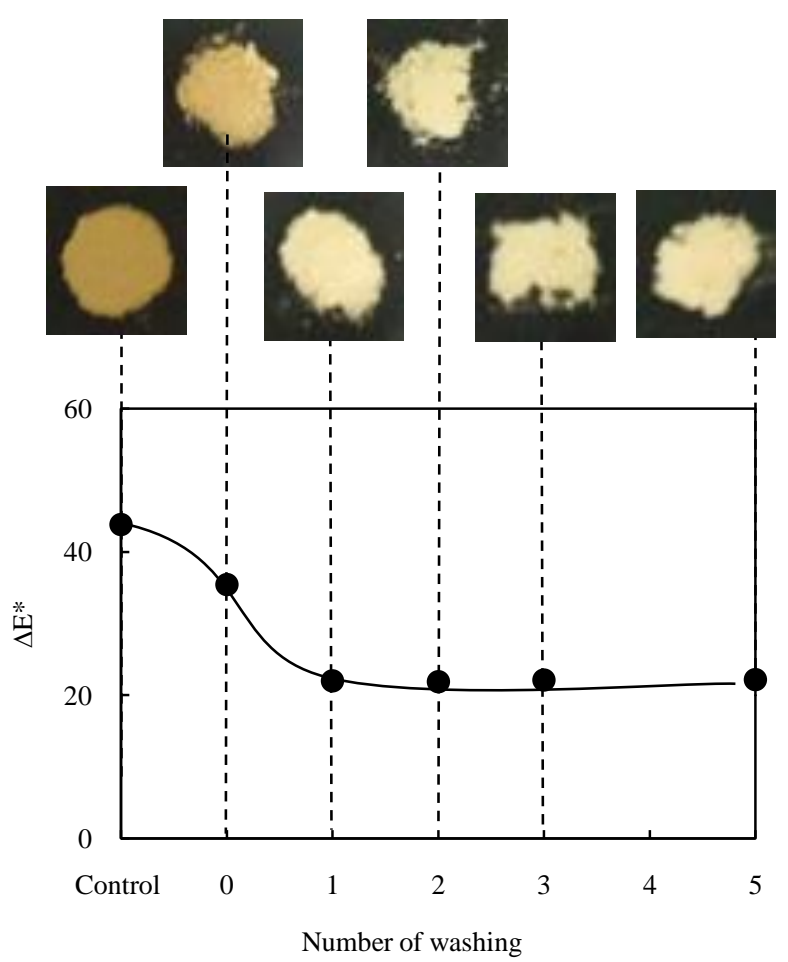

Figure 6. Influence of the number of washings of $\mathrm{NaBH}_{4}$-reduced Avicel $\mathrm{PH}-101$ on discoloration and total color difference $\left(\Delta \mathrm{E}^{*}\right)$ after heat treatment $\left(\mathrm{N}_{2} / 240{ }^{\circ} \mathrm{C} / 30 \mathrm{~min}\right)$. Washing condition: $0.001 \mathrm{~N} \mathrm{HCl}(2 \mathrm{~mL})$, then water $(5 \times 2$ $\mathrm{mL})$. 


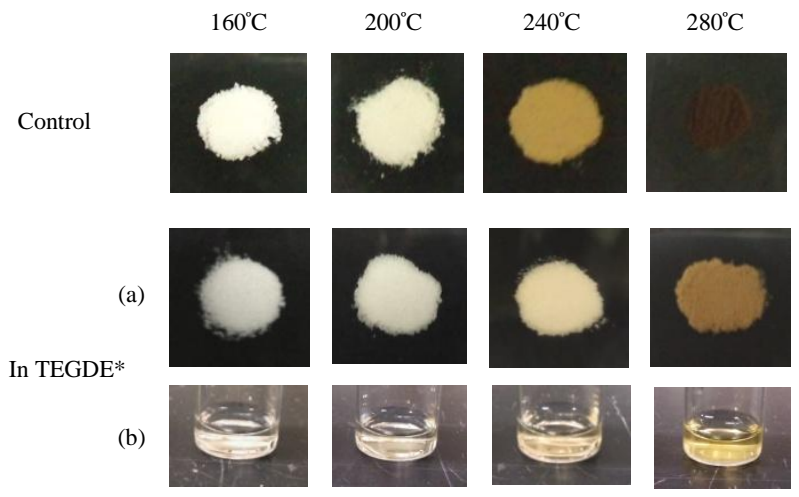

Figure 7. Discoloration of Avicel PH-101 heated in tetraethyleneglycol dimethylether (TEGDE) under $\mathrm{N}_{2}$ at various temperatures for $30 \mathrm{~min}$.

* Avicel PH-101 (100 mg)/TEGDE (200 mg). After heat treatment, the cellulose sample was filtered, washed with 1 $\mathrm{mL}$ water, then freeze-dried; (a) residual cellulose; (b) filtrate+washings. 

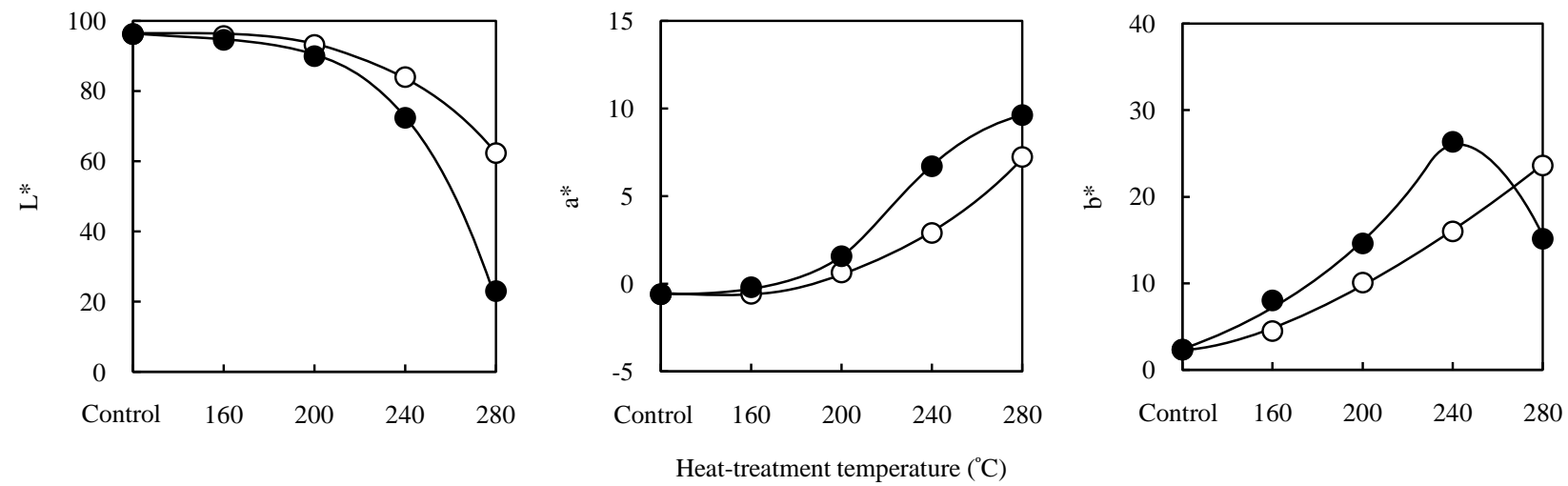

Figure 8. Changes of the CIE color parameters ( $\mathrm{L}^{*}, \mathrm{a}^{*}$, and $\mathrm{b}^{*}$ ) after heat treatment of Avicel PH-101 in the presence (open circles) or absence (closed circles) of tetraethyleneglycol dimethylether (TEGDE) under $\mathrm{N}_{2}$ at various temperatures for $30 \mathrm{~min}$. The sample preparation conditions are given in the footnote to Figure 7. 